\title{
Olbrzymia torbiel limfatyczna przestrzeni zaotrzewnowej w 10 lat po limfadenektomii
}

\author{
Anna Ptach ${ }^{1}$, Andrzej Sadowski ${ }^{2}$, Iwona Chruścicka ${ }^{3}$, Piotr Rak ${ }^{3}$
}

Usunięcie regionalnych węzłów chłonnych jest ważnym elementem w radykalnym leczeniu nowotworów. Następstwem regionalnej limfadenektomii jest powstawanie chłonkotoku, który u większości operowanych ustępuje samoistnie. Jednak u 12-32\% chorych przestrzeń, w której gromadzi się treść chłonna, przekształca się w torbiel limfatyczną. Postępowanie diagnostyczno-lecznicze w tych przypadkach uzależnione jest od wielkości i położenia torbieli limfatycznej.

W pracy przedstawiono 74-letnią chorą, u której rozpoznano i zaplanowano leczenie torbieli limfatycznej przestrzeni zaotrzewnowej. W oparciu o objawy kliniczne i wyniki badań obrazowych chorą zakwalifikowano do usunięcia torbieli limfatycznej przez laparotomię. Ocena śródoperacyjna potwierdziła słuszność decyzji przedoperacyjnej. Zabieg i okres pooperacyjny przebiegły bez powikłań. Prezentacja powyższego opisu przypadku wydaje się interesująca z uwagi na fakt, iż nawet po okresie 10 lat od operacji pierwotnej możliwe jest powstanie torbieli chłonnej, co należy brać pod uwagę w czasie prowadzenia badań kontrolnych u chorych onkologicznych.

\section{A enormous retroperitoneal lymphatic cyst in $\mathbf{1 0}$ years after lymphadenectomy}

The removal of regional lymph nodes is an important part of the radical treatment of certain cancers. In the majority of regional lymphadenectomies the consequence is the emergence of spontaneous lymphorrhoea. However, for $12-32 \%$ of patients, we observed that in the area of the lymphadenectomy, the content of the collected seroma is converted into a lymphatic cyst. Diagnosis and treatment in these cases is dependent on the size and location of the lymphatic cyst.

This case report describes a 74 year-old patient who was diagnosed with, and received treatment for, a retroperitoneal lymphatic cyst. On the basis of both clinical symptoms and imaging results, the patient was classified to receive removal of a lymphocele by laparotomy. Intraoperative evaluation further confirmed the validity of the preoperative decision. Both surgery and the postoperative period were uneventful. It is interesting that 10 years after the operation, primary absorbent cyst formation occurred in this patient's surgical area, a phenomena which should be considered as a possible outcome during the postoperative observation of oncological patients.

NOWOTWORY Journal of Oncology 2014; 64, 2: 187-190

Słowa kluczowe: torbiel limfatyczna przestrzeni zaotrzewnowej, leczenie chirurgiczne

Key words: retroperitoneal lymphocele, surgery treatment

\section{Wstęp}

Operacja radykalna jest podstawowym celem operacji onkologicznych, a jej zasadniczymi elementami są: usunięcie guza z marginesem tkanek makroskopowo zdrowych oraz usunięcie regionalnych węzłów chłonnych (axillary dissec- tion - AD) [1]. Następstwem AD jest obecność chłonkotoku, który ustępuje u większości operowanych samoistnie lub przybiera postać ograniczonej przestrzeni chłonnej, zwanej torbielą limfatyczną (lymphocele — LC). Jednak LC nie posiada własnej torebki, a jedynie torebkę rzekomą, i obserwowa-

${ }^{1}$ Szpitalny Oddział Ratunkowy, Szpital im. Św. Wincentego a Paulo w Gdyni 


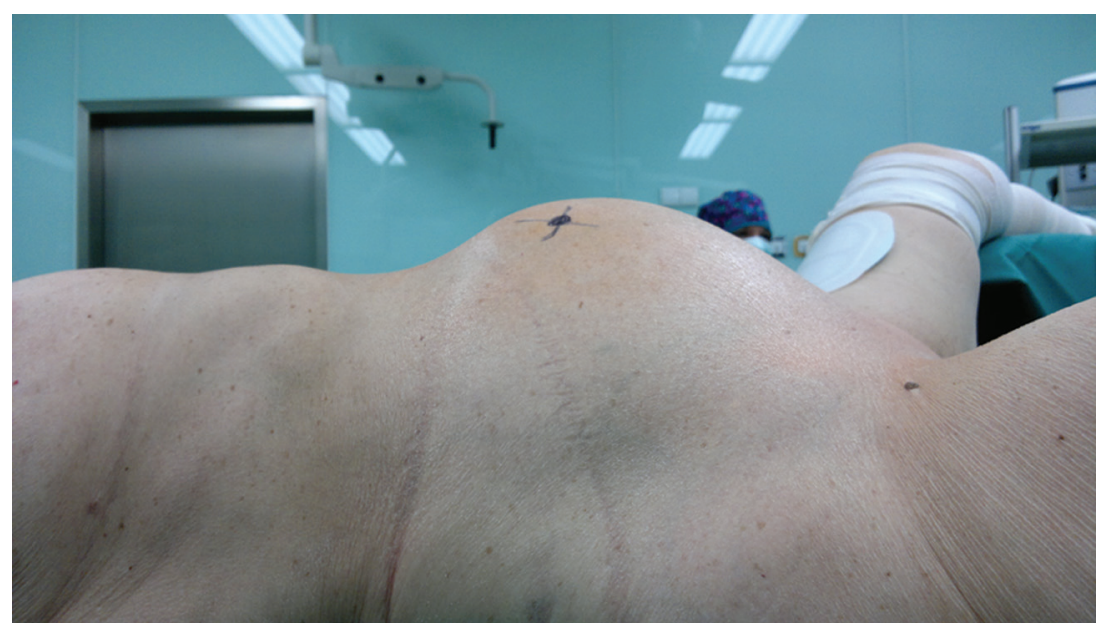

Rycina 1. Widok jamy brzusznej od strony prawej z powiększeniem obwodu brzucha spowodowanym obecnością torbieli limfatycznej

na jest ona u 12-32\% chorych, u których przeprowadzono regionalną i radykalną limfadenektomię. W zdecydowanej większości LC występuje po operacjach ginekologicznych [2-6]. Ponadto LC może występować między innymi po mastektomii z usunięciem węzłów pachowych u chorych na raka piersi oraz po operacjach przeszczepu nerki [7, 8].

Symptomatologia i leczenie LC uzależnione jest od ich wielkości oraz od położenia. Torbiele limfatyczne mogą przebiegać bezobjawowo lub mogą prowadzić do obrzęku i zakrzepicy żył głębokich kończyn dolnych, bólu, upośledzenia drożności moczowodów, zmniejszenia objętości pęcherza moczowego lub zaburzenia funkcji przewodu pokarmowego $[3,4]$. W przypadku małych i bezobjawowych torbieli proponuje się obserwację kliniczną lub obrazową, natomiast duże i objawowe LC kwalifikowane są do jednej z poniższych metod, takich jak: biopsja aspiracyjna cienkoigłowa, drenaż przezskórny, skleroterapia oraz chirurgiczne usunięcie LC z użyciem laparoskopii lub laparotomii $[4,9,10]$.

Celem pracy jest przedstawienie chorej operowanej z powodu objawowej torbieli przestrzeni zaotrzewnowej po przebytym zabiegu ginekologicznym z powodu raka trzonu macicy.

\section{Opis przypadku}

Chora lat 74 została przyjęta do kliniki z powodu olbrzymiej torbieli przestrzeni zaotrzewnowej, która była przyczyną znacznego powiększenia obwodu brzucha, okresowych bólów śródbrzusza oraz zaburzenia rytmu wypróżnień. Z wywiadu było wiadomo, że chora przebyła 11 lat wcześniej usunięcie macicy z przydatkami i limfadenektomią miedniczno-okołoaortalną z powodu raka trzonu macicy (wg klasyfikacji FIGO IC). Z uwagi na obecność złych czynników rokowniczych, takich jak: naciekanie powyżej połowy grubości ściany macicy, średni stopień zróżnicowania (G2) oraz naciekanie szyjki macicy, chora przebyła teleterapię z brachyterapią. W okresie 11 lat obserwacji onkologicznej nie stwierdzono cech wznowy choroby.

Po 10 latach od operacji ginekologicznej odnotowano zaburzenia rytmu wypróżnień i niespecyficzne bóle brzucha. W badaniu przedmiotowym stwierdzono powiększenie obwodu brzucha, z obecnością głównej masy w okolicy lewego podbrzusza (ryc. 1). W badaniu CT wykazano obecność guza w przestrzeni zaotrzewnowej wielkości (w największym wymiarze) $11,7 \mathrm{~cm}$, charakteryzującego się niską gęstością i niewzmacniającego się po dożylnym podaniu kontrastu. Dodatkowo stwierdzono znaczne przemieszczenie pętli jelitowych, naczyń krezkowych i lewego moczowodu, ale bez naciekania struktur sąsiednich (ryc. 2).W ultrasonografii wykonanej 6 miesięcy później stwierdzono powiększenie torbieli do $13,3 \mathrm{~cm}$. Z uwagi na narastające objawy kliniczne chorą zakwalifikowano do leczenia (usunięcia guza) z zastosowaniem laparotomii. Odstąpiono od małoinwazyjnych metod leczenia takich jak punkcja torbieli oraz usunięcie laparoskopowe z powodu położenia w przestrzeni zaotrzewnowej.

Zabieg operacyjny wykonywano w znieczuleniu ogólnym z ułożeniem chorej na wznak. Po otwarciu jamy brzusznej stwierdzono olbrzymią masę patologiczną, na której stwierdzono napiętą esicę wraz z jej krezką (ryc. 3A). Poza tym nie zaobserwowano rozsiewu choroby w obszarze narządów jamy brzusznej. W pierwszej kolejności oddzielono esicę wraz z naczyniami krezkowymi, a następnie uwidoczniono lewy moczowód. Torbiel usunięto w całości, bez jej uszkodzenia (ryc. 3B). W pooperacyjnym badaniu histopatologicznym potwierdzono rozpoznanie torbieli prostej o wymiarze $14 \mathrm{~cm}$ (ryc. 4).

Okres pooperacyjny był niepowikłany, a chorą wypisano w 3. dobie pooperacyjnej. W okresie 18 miesięcy obserwacji po zabiegu zaobserwowano ustąpienie wszystkich objawów z okresu przedoperacyjnego. 


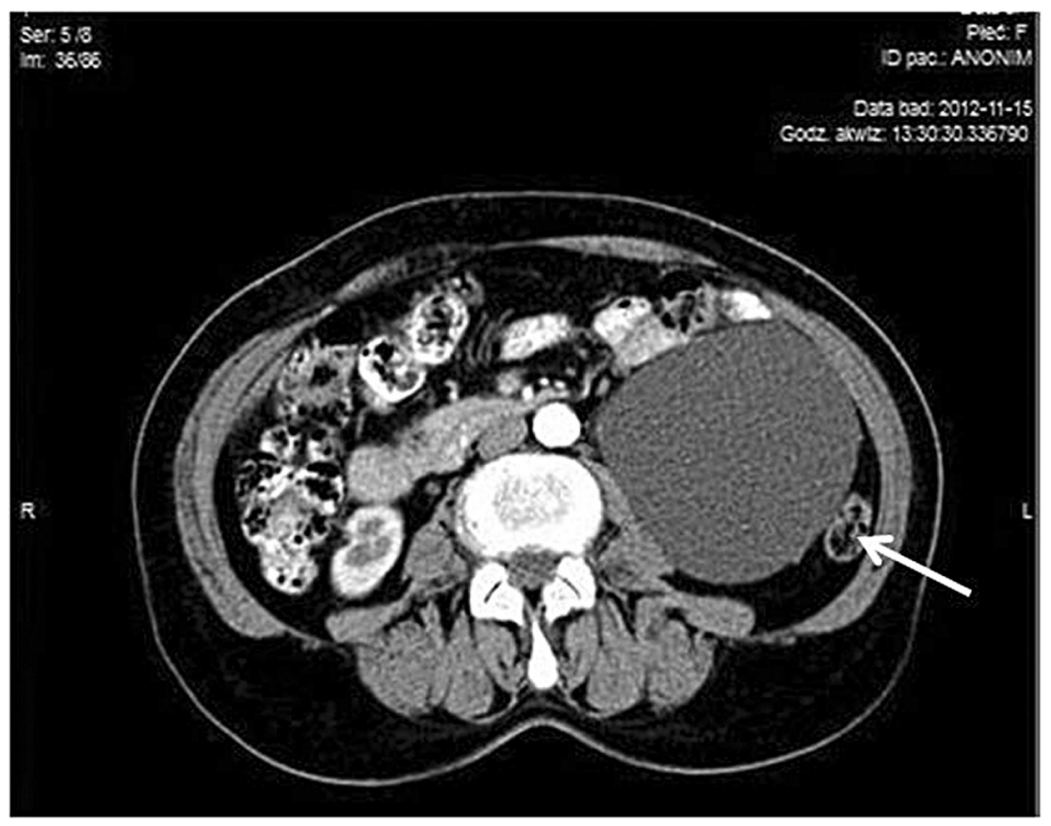

Rycina 2. Torbiel limfatyczna widoczna w badaniu tomografii komputerowej (strzałką oznaczono przemieszczone jelito grube)

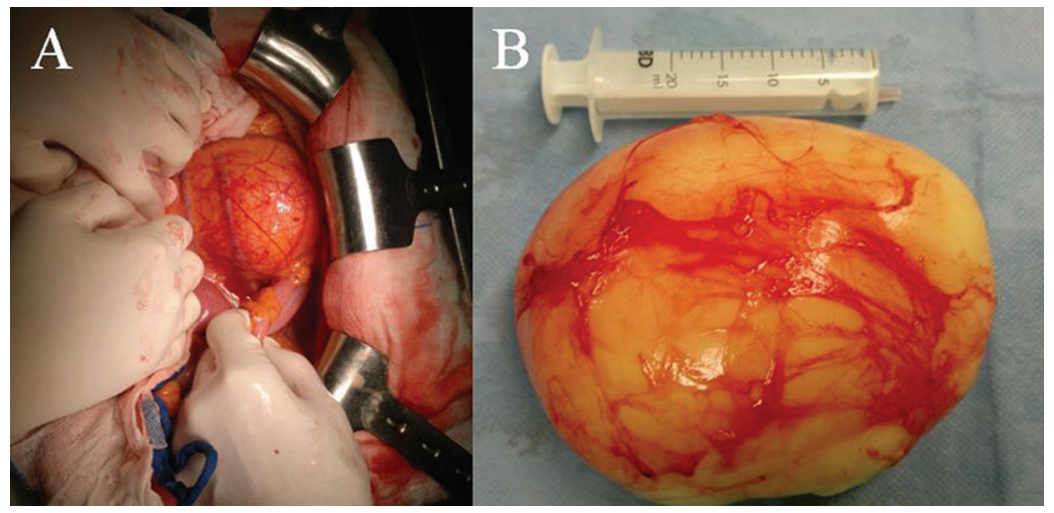

Rycina 3. Śródoperacyjny obraz torbieli limfatycznej widocznej po otwarciu jamy brzusznej (A) oraz po jej usunięciu (B)

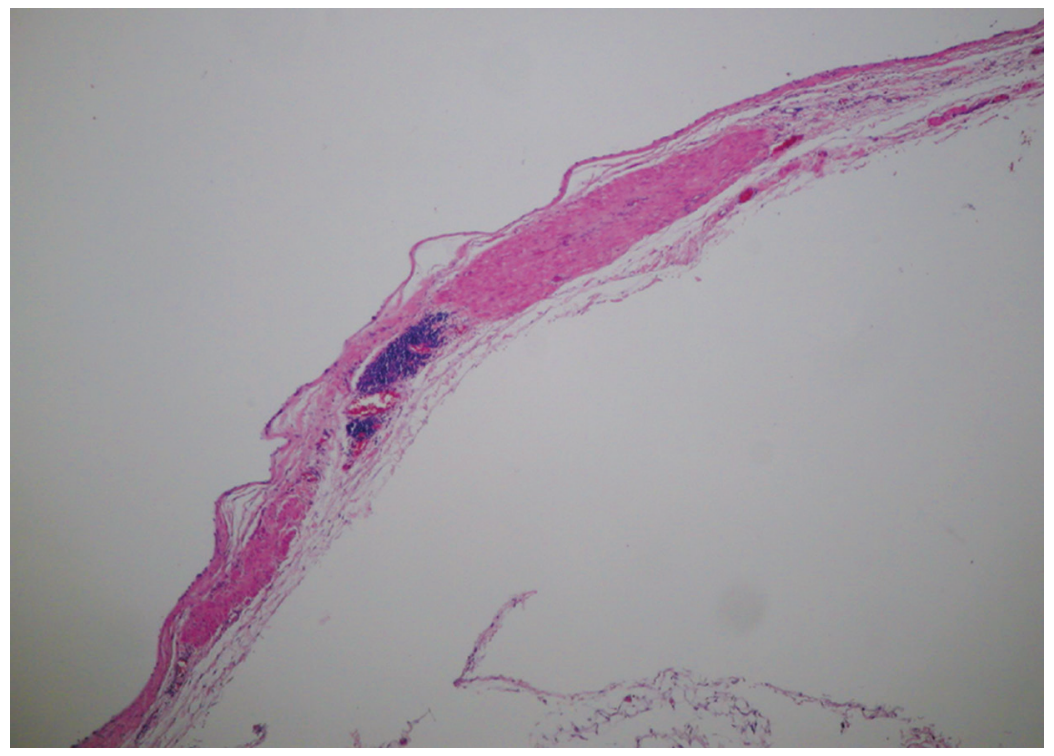

Rycina 4. Obraz mikroskopowy usuniętej torbieli limfatycznej 


\section{Omówienie}

W chirurgii onkologicznej, w tym również onkologii ginekologicznej, w celu radykalizacji zabiegu poza usunięciem guza nowotworowego usuwa się również regionalne węzły chłonne. W miejscu limfadenektomii dochodzi do tworzenia się chłonki, co jest objawem często spotykanym. W tych przypadkach pozostawienie drenażu w okolicy operowanej jest najlepszą metodą postępowania w celu ewakuacji krwi lub treści chłonnej. Na przykład po operacjach w obszarze jamy brzusznej, zgodnie z założeniami metody fast track, dreny są usuwane najczęściej w pierwszej dobie pooperacyjnej w przypadku braku aktywnego krwawienia [11]. Natomiast w chirurgii piersi, po wykonaniu mastektomii z limfadenektomią pachową, dreny są usuwane według doświadczenia ośrodków wykonujących te zabiegi, ponieważ nie ma wytycznych w zakresie czasu usuwania drenażu. Pomimo stosowania drenażu okolicy operowanej torbiele limfatyczne obserwuje się u 12-32\% chorych po limfadenektomii miednicznej i okołoaortalnej, a po mastektomii problem dotyczy niespełna kilku procent chorych [7].

Interesujące jest w prezentowanym przypadku późne powstanie torbieli limfatycznej w stosunku do operacji pierwotnej. Dopiero po 10 latach od zabiegu pierwotnego zaobserwowano objawy kliniczne, które skłoniły chorą do zgłoszenia się do chirurga onkologicznego. Według danych z literatury średni czas tworzenia się torbieli limfatycznej w przestrzeni zaotrzewnowej wynosi 2 lata [12-14].

Usunięcie regionalnych węzłów chłonnych jest jednym z najważniejszych elementów leczenia chirurgicznego nowotworów, a w szczególności w większości nowotworów piersi, przewodu pokarmowego, narządu rodnego oraz czerniaka. Jednak pomimo że w Polsce i na świecie najczęściej operowane są nowotwory piersi i płuc, to powstawanie torbieli limfatycznych częściej dotyczy chorych po operacjach ginekologicznych [2-6]. Obserwacja wielu autorów potwierdza się również w prezentowanym przypadku, w którym w czasie operacji pierwotnej wykonano usunięcie macicy z przydatkami wraz z limfadenektomią miedniczną i okołoaortalną.

Większość autorów jest zgodna, że leczenie torbieli limfatycznych powinno być wykonywane w ośrodkach posiadających ogromne doświadczenie zarówno w odpowiedniej kwalifikacji chorych do leczenia operacyjneg, jak i posiadających bardzo dobrą technikę operacyjną $[15,16]$. Dobór optymalnego leczenia chorych z torbielami chłonnymi jest możliwy dzięki interdyscyplinarnej współpracy chirurgów, radiologów i onkologów. Autorzy niniejszego artykułu pracują w Klinice, w której decyzje terapeutyczne również są wynikiem dyskusji wielospecjalistycznej [1, 17]. Powyższy opis chorej jest potwierdzeniem, że w chirurgii onkologicznej jednym z ważnych elementów leczenia jest indywidualizacja postępowania chirurgicznego [18, 19].

\section{Podsumowanie}

1. Leczenie torbieli limfatycznej wymaga funkcjonowania zespołu interdyscyplinarnego, którego zadaniem jest wybór optymalnego postępowania diagnostyczno-terapeutycznego.

2. W czasie prowadzenia obserwacji klinicznej chorych po usunięciu regionalnych węzłów chłonnych miednicy wraz z nowotworami jamy brzusznej, w różnicowaniu należy brać pod uwagę obecność torbieli limfatycznej.

Konflikt interesu: nie zgłoszono

Dr hab. n. med. Jacek Zieliński

Klinika Chirurgii Onkologicznej Gdańskiego Uniwersytetu Medycznego ul. Smoluchowskiego 17, 80-214 Gdańsk

e-mail:jaziel@gumed.edu.pl

Otrzymano: 24 lipca $2013 \mathrm{r}$.

Przyjęto do druku: 10 września 2013 r.

\section{Piśmiennictwo}

1. Zieliński J, Jaworski R, Kabata P i wsp. Gastric cancer in Poland: clinical characteristics and results of surgery. Dig Surg 2010; 27: 409-416.

2. Yang DM, Jung DH, Kim Hi wsp. Retroperitoneal cystic masses: $C T$, clinical, and pathologic findings and literature review. Radiographics 2004; 24: 1353-1365.

3. Franchi M, Trimbos JB, Zanaboni F i wsp. Randomised trial of drains versus no drains following radical hysterectomy and pelvic lymph node dissection: a European Organisation for Research and Treatment of Cancer-Gynaecological Cancer Group (EORTC-GCG) study in 234 patients. Eur J Cancer 2007; 43: 1265-1268.

4. Mahrer A, Ramchandani P, Trerotola SO i wsp. Sclerotherapy in the management of postoperative lymphocele. J Vasc Interv Radiol 2010; 21: 1050-1053.

5. Logmans A, Kruyt RH, de Bruin HG i wsp. Lymphedema and lymphocysts following lymphadenectomy may be prevented by omentoplasty: A pilot study. Gynecol Oncol 1999; 75: 323-327.

6. Petru E, Tamussino K, Lahousen M i wsp. Pelvic and paraaortic lymphocysts after radical surgery because of cervical and ovarian cancer. Am J Obstet Gynecol 1989; 161: 937-941.

7. Zielinski J, Jaworski R, Irga N i wsp. Analysis of selected factors influencing seroma formation in breast cancer patients undergoing mastectomy. Arch Med Sci 2013; 9: 86-92.

8. Ulrich F, Niedzwiecki S, Fikatas P i wsp. Symptomatic lymphoceles after kidney transplantation - multivariate analysis of risk factors and outcome after laparoscopic fenestration. Clin Transplant 2010; 24: 273-280.

9. Metcalf KS, Peel KR. Management of postoperative pelvic lymphocele. Urology 1980; 15 : 345-347.

10. Gill IS, Hodge EE, Munch LC i wsp. Transperitoneal marsupialisation of lymphocele: a comparison of laparoscopic and open techniques. JUrol 1995; 153: 706-711.

11. Zygoń J, Gołąbek-Dropiewska K, Sowa M i wsp. Technika fast track — zastosowanie u pacjentów poddawanych elektywnym operacjom jelita grubego. Nowotwory J Oncol 2011; 61: 150-158.

12. Scholz HS, Petru E, Benedicic C i wsp. Fibrin application for preventing lymphocysts after retroperitoneal lymphadenectomy in patients with gynecologic malignancies. Gynecol Oncol 2002; 84: 43-46.

13. Terada KY, Roberts JA. Lymphoceles following second-look laparotomy for ovarian cancer. Gynecol Oncol 1988; 29: 382-384.

14. Conte M, Panici PB, Guariglia L i wsp. Pelvic lymphocele following radical para-aortic and pelvic lymphadenectomy for cervical carcinoma: incidence rate and percutaneous management. Obstet Gynecol 1990; 76: 268-271.

15. Zieliński J, Świerblewski M, Kruszewski WJ i wsp. Doświadczenia jednego ośrodka klinicznego w chirurgicznym leczeniu raka płaskonabłonkowego przełyku w latach 1970-2007. Kardiochir Torakochir Pol 2011; 8: 71-76.

16. Jaworski R, Haponiuk I, Chojnicki M i wsp. Program poprawy higieny rąk na oddziale kardiochirurgii dziecięcej. Kardiochir Torakochir Pol 2012; 2: 278-282.

17. Jaworski R, Bollschweiler E, Holscher AH i wsp. Prognostic relevance of demographics and surgical practice for patients with gastric cancer in two centers: in Poland versus Germany. Gastric Cancer 2011; 14: 234-241.

18. Zieliński J, Jaworski R, Pawlaczyk R i wsp. Simultaneous surgery for critical aortic stenosis and gastric cancer: a case report. World J Gastroenterol 2010; 16: 1161-1164.

19. Jaworski R, Zieliński J, Gross M i wsp. Olbrzymi guz stromalny przewodu pokarmowego: opis przypadku. Nowotwory J Oncol 2008; 58: 59-61. 